RAD Conference Proceedings, vol. 2, pp. 276-282, 2017

www.rad-proceedings.org

novororitty

\title{
SENSITIVITY OF REMOTELY-SENSED SPECTRAL REFLECTANCE TO BIOPHYSICAL VARIABLES OF PLANTS
}

\author{
Kalinka Velichkova', Dora Krezhova2* \\ ${ }^{1}$ University of Mining and Geology “St. Ivan Rilski”, Bulgaria, Sofia, Bulgaria \\ ${ }^{2}$ Space Research and Technology Institute, Bulgarian Academy of Sciences, Sofia, Bulgaria
}

\begin{abstract}
Estimation and monitoring of plant health and influence of the environment are important components of the climate change researches. Recent hyperspectral remote sensing technologies, based on measurements of leaf reflectance in the visible and near infrared spectral ranges, allow detecting subtle absorption features in foliar spectra and to study correlations of these features linked to plant biophysical variables. The purpose of this study is to explore the sensitivity of several narrowband vegetation indices (VIs) when used to estimate the effect of a biotic stress (viral infection) on the biophysical parameters and physiological state of young potato plants. Two groups of plants were investigated - healthy and infected with Potato Virus Y (PVY). Hyperspectral reflectance data were collected by means of a portable fiber-optics spectrometer in the spectral range 400-110o $\mathrm{nm}$ with a spectral resolution of $1.5 \mathrm{~nm}$. The VIs - Normalized Difference VI (NDVI), modified Normalized Difference VI (mNDVI), Simple Ratio (SR); Chlorophyll Absorption Ratio Index (CARI), Modified CARI (MCARI), Chlorophyll Indices (ChI green and $C h I_{\text {red edge }}$ ); Pigment index (PI), Disease index $\left(f_{D}\right)$ and Photochemical Reflectance Index (PRI) were evaluated for their potential to detect changes in physiological state and biochemical content of the infected plants. Three VIs appeared to be most sensitive - CARI, ChI green, and MCARI, the latter one has shown about two time better sensitivity than the others.
\end{abstract}

Key words: Hyperspectral leaf reflectance, remote sensing, vegetation indices, viral infection, biophysical variables

DOI: $10.21175 / \operatorname{RadProc} .2017 .56$

\section{INTRODUCTION}

The estimation of changes in the biophysical parameters and leaf biochemistry in high-value crops and orchard trees has important potential applications for agricultural field management, crop stress, and especially for precision agricultural practices. The leaf biochemical constituents, such as chlorophyll (Chl) and other pigment concentrations, dry matter, water and nitrogen $(\mathrm{N})$ content, may be used as indicators of crop stress through their potential influence on nutritional deficiencies [1].

Traditionally, stress-induced changes in plants have been mainly investigated by visual inspection or detected after extensive analysis of destructive samplings during the growth period [2]. Contemporary hyperspectral remote sensing (HRS) methods based on reflectance measurements in the visible (VIS) and near infrared (NIR) regions of the electromagnetic spectrum allow real-time plant monitoring and detection of stress impacts even before the appearance of visual symptoms and the occurrence of adverse effects. There is valuable information in the reflectance spectra which relates to the biophysical and biochemical parameters of both the leaf composition and the canopy properties [3]. The concentration of foliar pigments [4], $\mathrm{N}$ concentration [5], water content [6], and leaf area index (LAI) [7] are the main variables related to the plant physiological state. Plants with limited N-uptake will have a lower $\mathrm{Chl}$ concentration which is an indicator for non-optimal photosynthesis [8]. In this context, HRS data showed already a high potential for the spatial and non-destructive estimation of leaf biochemical components.

Collecting vegetation canopy spectra to monitor their changes over time, translating them into biophysical and biochemical parameters of interest, and relating these parameters to environmental limiting factors are three main aspects of vegetation remote sensing [9].

Hyperspectral reflectance data provides simultaneous acquisition of information in narrow but continuous spectral bands which are sufficient to detect subtle absorption features in foliar spectra and to study correlations of these features to biophysical and biochemical parameters [10]. To translate hyperspectral reflectance data into information about these parameters, specialized algorithms and approaches are needed. Two common approaches are the statistical approaches [11] and the physical modeling [12]. The statistical approaches include spectral vegetation indices (VIs) computation and

*dora.krezhova@gmail.com 
regression model application. The physical modeling consists of applying radiative transfer models that are based on physical laws and they have been widely used to retrieve vegetation parameters from various types of remote sensing data.

The increasing importance of hyperspectral reflectance data motivated researches to define optimal wavebands for estimation of plant biophysical parameters [13]. In most of the investigations optical VIs were used that summarize the information contained in the reflectance spectra through combinations of reflectance at different wavelengths. A large number of narrowband VIs, derived from hyperspectral measurements, was developed by allowing several combinations for each of the biophysical variables [14]. The use of VIs may improve the sensitivity to vegetation parameters investigated by minimizing the influence of extraneous factors and reduce the abundance of data sets.

The present study aims to explore the sensitivity of several narrowband vegetation indices used to analyse the influence of a biotic stress (viral infection), caused by Potato Virus Y (PVY) on the biophysical parameters and physiological state of young potato plants. The VIs were calculated from hyperspectral reflectance data at several wavelengths in green, red edge and NIR spectral ranges. The datasets were obtained from ground-level hyperspectral reflectance measurements of plants at the stage of infection without visual symptoms on the leaves.

\section{MATERIALS AND METHODS}

\subsection{Plant material}

Fresh detached leaves from young potato plants, cultivar Armada, were used for the investigations. The plants were grown in greenhouse conditions $\left(24^{\circ} \mathrm{C}\right.$, air humidity $45 \%$, photoperiod of $16 / 8 \mathrm{~h}$ ). Some of the plants were infected with Potato virus Y (PVY). It is one of the most important viruses infecting potatoes and, in principle, it causes mosaic, chlorotic, and necrotic symptoms on leaves and tuber malformations [15]. The inoculation of the plants was carried out according to Noordam [16]. Some of the plants were non-infected (healthy) and treated as control. The infected plants developed without signs of disease of the aerial parts.

\subsection{Remote sensing of vegetation biophysical parameters}

Variability of the optical properties of the plants is wavelength-dependent. Photosynthetically active vegetation absorbs most of the red incident light while reflecting much of the NIR light. Fig. 1 shows the typical reflectance curve of green vegetation and the main factors which influence leaf reflectance [17].

Usually, spectral analyses are performed from 400 $\mathrm{nm}$ to $2500 \mathrm{~nm}$ in three parts of the electromagnetic spectrum: VIS (400-700 $\mathrm{nm}$ ), characterized by strong absorption of light by photosynthetic pigments in green leaves, mainly of Chl content; NIR (700-1100 nm), where absorption is limited to dry leaf matter and multiple scattering within the leaf related to the internal cell structure; and shortwave infrared (SWIR, $1100-2500 \mathrm{~nm}$ ), which is also a zone of strong absorption, primarily by water in fresh leaves and secondarily, by dry matter (dry carbon compounds like cellulose and lignin, nitrogen, sugars, and other plant compounds) when the leaf wilts and dries [18].

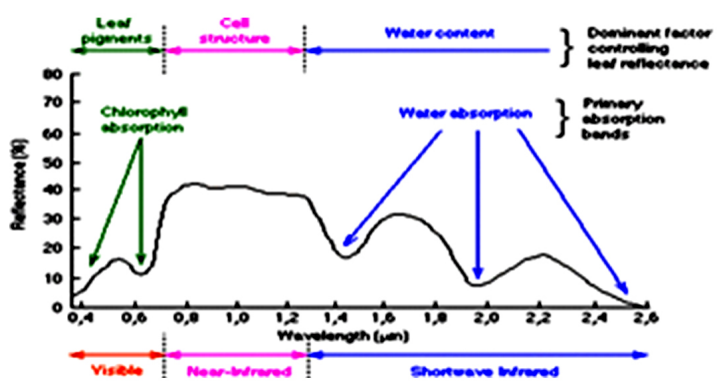

Figure 1. Typical spectral reflectance curve of green vegetation and main factors influencing reflectance

From the optical point of view, the dominant leaf pigments Chl $a$ and $b$ and carotenoids have different spectral behaviour, with specific absorption features at different wavelengths, which allows remote sensing techniques to discriminate their respective effects on vegetation reflectance spectra. Chls absorb most strongly in the blue and red wavebands. Vegetation that is dead or stressed reflects more light in the red region and less in NIR. At the same time, nonvegetated surfaces have a much more even reflectance across the optical spectrum. Since the blue peak overlaps with the absorbance of the carotenoids, it is not generally used for estimation of Chl content. Maximal absorbance in the red region occurs between $650 \mathrm{~nm}$ and $680 \mathrm{~nm}$. Photosynthesis is closely linked to $\mathrm{Chl}$ levels. Some environmental stresses reduce photosynthesis with entailed reduction of the concentration of leaf $\mathrm{Chl}$, which could be detected as increased reflectance in the blue (e.g., reflectance at $420 \mathrm{~nm}$ ) and red (e.g., reflectance at $670 \mathrm{~nm}$ ) wavebands [19]. The empirical models for prediction of Chl content from reflectance are largely based on reflectance in the $550 \mathrm{~nm}$ or $700 \mathrm{~nm}$ regions where higher $\mathrm{Chl}$ contents are required to saturate the absorbance [20]. Since anthocyanin also absorbs around $550 \mathrm{~nm}$, VIs based on absorbance of around $700 \mathrm{~nm}$ are more suitable for predicting the Chl content. Increased leaf $\mathrm{Chl}$ content has been shown to increase the red edge - the reflectance between wavelengths of maximum slope at the red/NIR transition [21].

\subsection{Leaf reflectance measurements}

Spectral measurements of the reflected radiation from healthy and PVY infected potato plants were carried out by means of a portable fibre-optic spectrometer USB2000 (Ocean Optics, USA) [22]. Hyperspectral reflectance data were collected in the VIS and NIR spectral ranges (400-1100 $\mathrm{nm}$ ) at a spectral resolution of $1.5 \mathrm{~nm}$. Data analyses were performed in spectral range 450-850 $\mathrm{nm}$ (most informative for green plants) in 1170 narrow spectral bands with a sampling interval of $0.3 \mathrm{~nm}$. Fresh detached leaves (about 30) from two potato groups (control and infected) were measured in laboratory on an experimental setup on the $7^{\text {th }}$ day after the inoculation with PVY [23]. The light source was a 
halogen lamp providing homogeneous illumination of the leaf surfaces. The spectral reflectance characteristics (SRC) of the investigated plants were determined by the ratio between the radiation reflected from the leaves and the radiation reflected from the diffuse reflectance standard. Specialized software was used for data acquisition and processing.

\subsection{Narrowband vegetation indices}

Vegetation indices have served as the basis for many applications of remote sensing to crop management. They have been developed as the mathematical combination (linear and non-linear) of leaf reflectance at various discrete wavebands and related to various canopy parameters. In many of applications of VIs the researches seeking to enhance the leaf reflectance signal while minimizing the solar irradiance and soil background effects [24].

Three primary types of VIs were developed in relevant bibliography: structural, calculated as simple ratios (SR) and normalized differences; Chl/Pigment related indices, calculated with similar mathematical combinations; and red edge indices, analysing changes in red edge position.

Combining individual spectral reflectance bands as SR, VIs have been a common approach in remote sensing because it generally reduces the effects of spectral noise and allows better temporal comparisons due to the minimization of atmospheric effects [25]. The first proposed VI was the NIR/red ratio [26]. Commonly, SR VIs have consisted of the ratio of blue to red wavebands in an effort to detect responses due to the changes in Chl $a$ and $b$ concentrations. Tilley et al. [27] found that $S R=R_{493} / R_{678}$ was indicative of marsh ammonia levels based on cattail reflectance. Carter [25] defined $S R=R_{695} / R_{420}$ as an index for detecting plant stress caused by water and nutrient deficiencies. Tucker [28] defined $\mathrm{SR}=\mathrm{R}_{845} / \mathrm{R}_{665}$ as index of green vegetation cover. For our investigations we used SR:

$$
S R=\frac{R_{760}}{R_{695}},
$$

because the changes acquired in the reflectance spectra of infected with PVY potato plants around these wavelengths are indicators for injury of the plants [21].

The Normalized Difference Vegetation Index (NDVI), defined as a ratio of $\left(\mathrm{R}_{\mathrm{NIR}}-\mathrm{Rred}\right) /\left(\mathrm{R}_{\mathrm{NIR}}+\right.$ Rred), where NIR $=845 \mathrm{~nm}$, red $=665 \mathrm{~nm}$, was found as an estimator of LAI in canopies[29]. Reflectance in the red and NIR regions are affected by two important vegetation components - pigments (specifically Chl) and leaf structure. NDVI is one of the most commonly used VIs for biomass estimation or plant "greenness" [30]. A higher NDVI indicates more leaf biomass or a higher LAI. Many factors affect NDVI values like plant photosynthetic activity, total plant cover, biomass, plant and soil moisture, and plant stress. For data analyses we used combination:

$$
N D V I=\frac{R_{765}-R_{685}}{R_{765}+R_{685}} .
$$

Modified NDVI (mNDVI) with wavelength of 705 nm quantify Chl content and is sensitive to low content at leaf level [31].

$$
m N D V I=\frac{R_{750}-R_{705}}{R_{750}+R_{705}} .
$$

Vis defined by eq. 2 and eq. 3 are suitable for our investigation because they give information about plant greenness and plant stress.

The assessment of the Chl content of crop canopies has included the Normalized Pigment Chlorophyll ratio Index (NPCI) defined as $\left(\right.$ red $_{680}-$ blue $\left._{430}\right) /\left(\operatorname{red}_{680}+\right.$ blue $_{430}$ ) [32]. The form of this index is similar to the NDVI. The studies using optical VIs for Chl estimation have focused on evaluating the reflectance in individual narrow bands, band reflectance ratios and combinations, and the characteristics of derivative spectra. For our analysis we used $\mathrm{Chl}$ indices proposed by [33]:

$$
\begin{aligned}
& C h I_{\text {green }}=\frac{R_{\text {NIR }}}{R_{\text {green }}}-1, \\
& C h I_{\text {red edge }}=\frac{R_{\text {NIR }}}{R_{\text {red edge }}}-1,
\end{aligned}
$$

where: green $=550 \mathrm{~nm}$, red $=714 \mathrm{~nm}$ and $\mathrm{NIR}=760 \mathrm{~nm}$.

Chlorophyll Absorption Ratio Index (CARI) was designed to reduce the variability of the photosynthetically active radiation due to the presence of diverse non-photosynthetic materials. It uses bands corresponding to the minimum absorption of the photosynthetic pigments, centred at $550 \mathrm{~nm}$ and 700 $\mathrm{nm}$, in conjunction with the Chl a maximum absorption band, around $670 \mathrm{~nm}$ [27].

$$
C A R I=\left[\left(R_{700}-R_{670}\right)-0.2\left(R_{700}-R_{550}\right)\right]
$$

The modified CARI (MCARI) is a measure of the depth of Chl absorption at $670 \mathrm{~nm}$ relative to the reflectance at 550 and $700 \mathrm{~nm}$ [14], and is quantified by equation:

$$
\begin{aligned}
M C A R I & =\left[\left(R_{700}-R_{670}\right)\right. \\
& \left.-0.2\left(R_{700}-R_{550}\right)\right] \frac{R_{700}}{R_{670}} .
\end{aligned}
$$

Our interest in CARI and MCARI was motivated by their potential to be responsive to Chl variation and resistant to non-photosynthetic materials effects.

Pigment indices (PI) are focused on photosynthetic pigments, primarily Chl. Leaves possess also a range of accessory photosynthetic pigments, including carotenoids and xanthophylls that serve functions to regulate and increase photosynthetic performance. For data analyses we used PI, defined as:

$$
P I=\frac{R_{N I R}}{R_{r e d}},
$$

where: $\mathrm{NIR}=677 \mathrm{~nm}$ and red $=554 \mathrm{~nm}$.

The photochemical reflectance index (PRI), originally was developed by Gamon et al. [34] to estimate rapid changes in the relative levels of xanthophyll cycle pigments, i.e. for estimation of photosynthetic efficiency. Sims [35] found that PRI 
was related to carotenoid/Chl ratios in green leaves. It is defined as follow:

$$
P R I=\frac{R_{531}-R_{570}}{R_{531}+R_{570}} .
$$

Since PRI measures the relative reflectance on either side of the green hump $(550 \mathrm{~nm})$, it also compares the reflectance in the red and blue regions of the spectrum which give information related to plant state.

When plants are stressed or diseased the stress factors interfere with photosynthesis or the physical structure of the plants, affecting the absorption of light leading to an alteration in the reflectance spectrum. Disease indices $f_{D}$ are specific for individual study. In our case we defined:

$$
f_{D}=\frac{R_{500}}{R_{500}+R_{570}} .
$$

\section{RESULTS AND DISCUSSION}

To assess the influence of viral infection on the spectral behaviour and biophysical parameters of the infected with PVY potato plants ten VIs (equations 1 to 10) were calculated. The spectral regions that are identified as the most suitable to Chl effects study are those around $680 \mathrm{~nm}$, corresponding to absorption peak of Chl $a$, and $550 \mathrm{~nm}$ matching with the minimum Chl absorption in the visible domain [36]. The choice of $700 \mathrm{~nm}$ is due to its location at the boundary between the region where vegetation reflectance is dominated by pigments absorption and the beginning of the red edge portion where vegetation structural characteristics have more influence on the reflectance [37].

To illustrate the significance of the differences between the reflectance data of healthy and infected potato leaves cluster analyses were performed on the sets of data at wavelengths $550 \mathrm{~nm}$ and $700 \mathrm{~nm}$ (Fig. 2 a) and at wavelengths $680 \mathrm{~nm}$ and $700 \mathrm{~nm}$ (Fig. $2 \mathrm{~b}$ ). In two cases two nearby clusters are formed for two groups of spectral data.

The sensitivity of calculated narrowband VIs to changes appearing in PVY infected potato plants was evaluated by applying statistical analyses on their sets of values (about 30 for all measured leaves). The mean values of each VI of control and infected potato plants, the differences between means, and the results of statistical analyses are displayed in Table 1.

Statistical significance of the differences between calculated VIs of control and infected leaves, treated as independent variables, was established by means of extended Student's t-test and F-test. F-test compares the variances of two varieties. F-values are calculated as a ratio of variances of two compared groups (squares of standard deviations). T-test was performed at level of statistical significance $\mathrm{p}<0.05$. LSD . $05_{\text {(Least }}$ Significant Difference) is the value at a particular level of statistical probability (e.g. p $\leq 0.05$ - means with $95 \%$ accuracy). The difference between two means for each VIs is declared as significant at a desired level of significance if it exceeds the value of derived LSD. a)

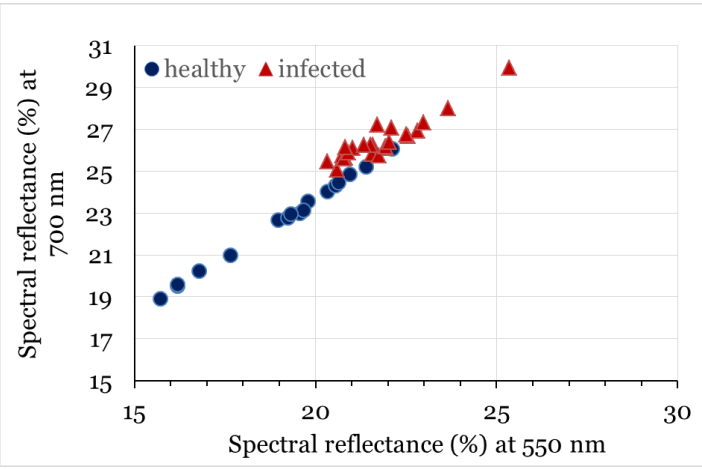

b)

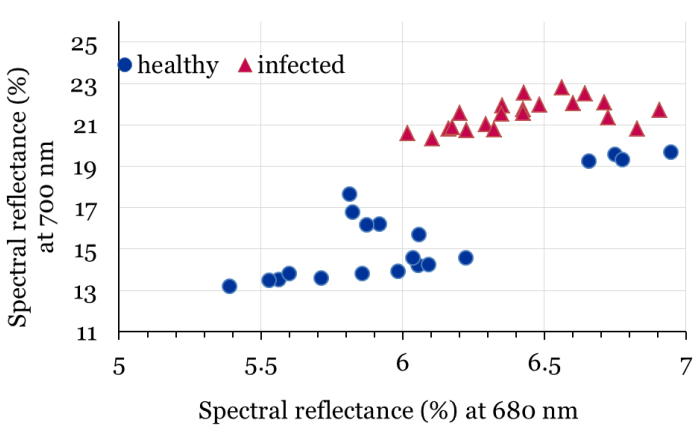

Figure 2. Cluster analyses on the spectral reflectance data of control and infected potato leaves at wavelengths: a) $550 \mathrm{~nm}$ and 700nm; b) $680 \mathrm{~nm}$ and $700 \mathrm{~nm}$

The results showed that NDVI was insensitive to the viral infection in an early stage. Eq. 2 is based on the contrast between the maximal absorption in the red region due to Chls and the maximal reflection in the NIR caused by leaf cellular structure. Theoretically, NDVI values are represented as a value ranging in from -1 to 1 ; however, in practice, extreme negative values represent the water and values around zero represent bare soil [33]. Values over o.6 represent dense green vegetation. In our case, the NDVI values for two plant groups are close - about 0.8 . This result correlated with the fact that infected plants were without visible symptoms during the measurements, i.e. with similar 'greenness'.

The mNDVI (eq. 3) and SR (eq. 1) VIs are sensitive to changes in biophysical parameters. These indices allow Chl estimation in dark green to yellow leaves within a wide range of pigment variation. It was also reported that the index $R_{760} / R_{695}$ is a sensitive indicator of plant stress and it is low for soil, ice, and water [38]. The statistical analyses indicate the presence of small changes of the Chl content in the infected leaves. In our case, SR value is high (about 7), but it is lower for infected leaves (18\%).

Chl VIs present the ratio between the spectral reflectance in wavelength ranges: green $(520-585 \mathrm{~nm})$ or in range $(550 \mathrm{~nm} \pm 20 \mathrm{~nm})$, red $(695-740 \mathrm{~nm})$ or in range $(715 \mathrm{~nm} \pm 20 \mathrm{~nm})$, and NIR - wavelength more than $750 \mathrm{~nm}$ [39]; they are individual for measured reflectance data. Our results show that ChI (eq. 4 and eq. 5) are sensitive to the physiological state of plants and to reduction of the Chl content. This is in 
accordance with the changes in all of measured reflectance data in green, red, and NIR spectral regions.

As a result of all applied statistical analyses, VIs CARI and MCARI show best sensitivity to the changes in biophysical parameters and plant physiological state. CARI and its modification measure the depth of Chl absorption at $670 \mathrm{~nm}$ relative to the green reflectance peak at $550 \mathrm{~nm}$ and the reflectance at 700 $\mathrm{nm}$. The most significant changes in the measured reflectance spectra $(450-850 \mathrm{~nm})$ were assessed in red and NIR spectral ranges.

PI (eq. 8) directly compares signals between the reflection and absorption peak of Chl pigments, which mean that it is sensitive to the changes in Chl content.

Disease index $f_{D}$ shows good results for stress detection in an early stage. PRI (eq. 9) was found to be also insensitive. PRI is sensitive to carotenoid/Chl ratio [35]. In our case, the changes in this pigment ratio are non-significant.

Table 1. Mean values of hyperspectral VIs used in the study, p- values, F-values, and LSD at level p=0.05 (95\%)

\begin{tabular}{|c|c|c|c|c|c|c|c|c|c|c|}
\hline VIs & NDVI & mNDVI & SR & CARI & MCARI & Chl green & Chl red edge & PI & PRI & $f_{D}$ \\
\hline $\begin{array}{c}\text { mean } \\
\text { healthy }\end{array}$ & 0.845 & 0.516 & 7.283 & 11.343 & 31.064 & 2.938 & 0.886 & 0.310 & 0.021 & 0.270 \\
\hline $\begin{array}{c}\text { mean } \\
\text { infected }\end{array}$ & 0.829 & 0.420 & 5.239 & 16.170 & 53.845 & 1.858 & 0.614 & 0.243 & 0.017 & 0.254 \\
\hline $\mathrm{F}$ & 1.142 & 3.622 & 5.360 & 8.281 & 4.529 & 9.480 & 7.514 & 12.317 & 1.087 & 7.880 \\
\hline $\mathrm{p}$ & $\mathrm{ns}$ & $* *$ & $* *$ & $* * *$ & $* * *$ & $* * *$ & $* * *$ & $* * *$ & $\mathrm{~ns}$ & $*$ \\
\hline LSD 0.05 & 0.007 & 0.020 & 0.448 & 1.013 & 3.934 & 0.204 & 0.064 & 0.009 & 0.002 & 0.0059 \\
\hline diference & 0.017 & 0.095 & 2.045 & 4.827 & 22.781 & 1.080 & 0.273 & 0.068 & 0.003 & 0.016 \\
\hline
\end{tabular}

ns - no statistical significance; ${ }^{*}-\mathrm{p}<0.05{ }^{* *}$ - p<0.01; ${ }^{* * *}-\mathrm{p}<0.001$

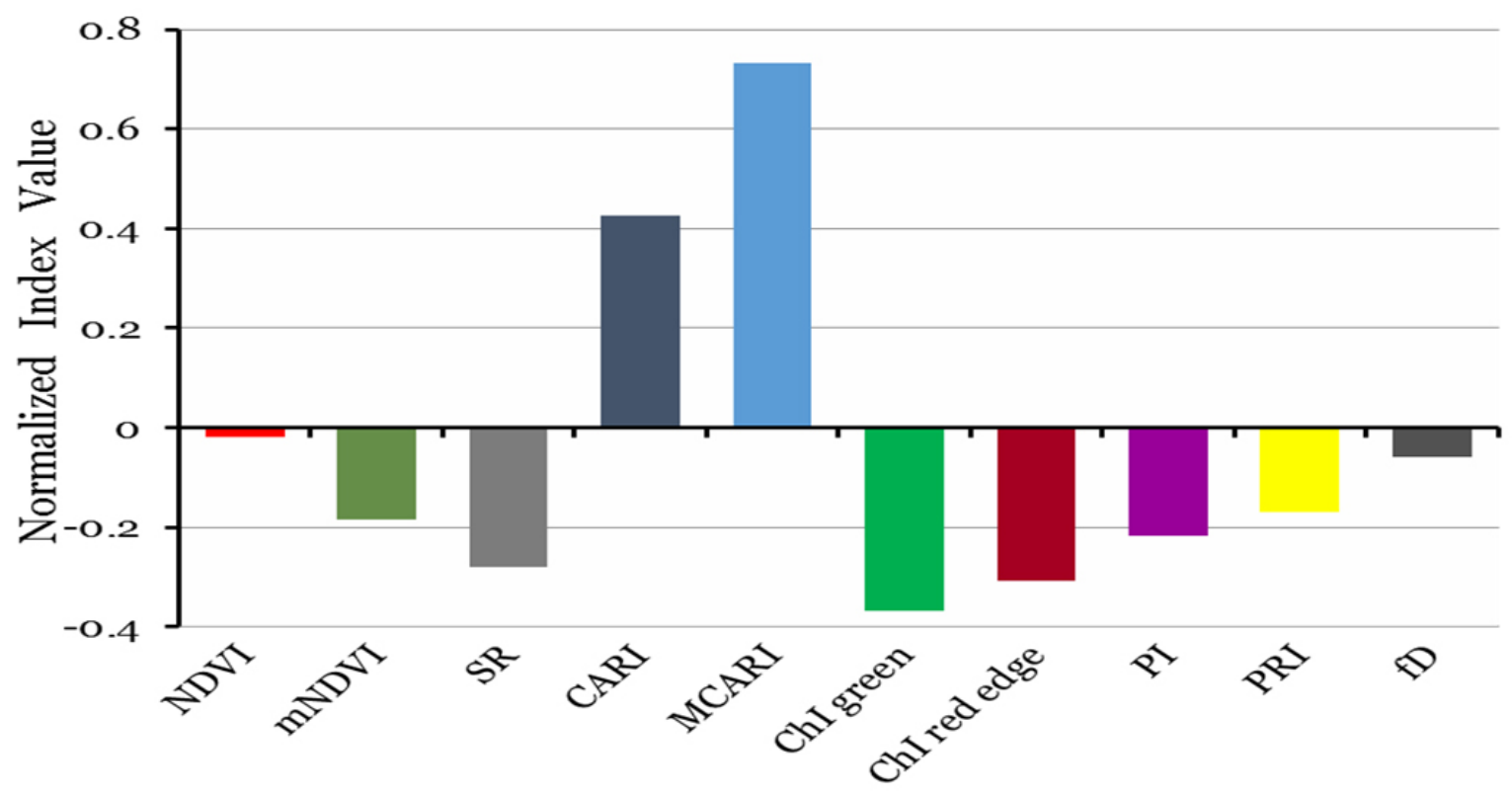

Figure 3. Normalized differences of vegetation indices of the infected group compared to the control group

The normalized differences between the mean VI values of the infected and healthy potato leaves are displayed in Figure 3. The best sensitivity demonstrated MCARI, followed by CARI and ChI green. MCARI has shown about two times better sensitivity than the others two VIs.

\section{CONCLUSIONS}

In this study the responses of young potato plants to a biotic stress (viral infection at an early stage) were analysed. Remote sensing technique of spectral reflectance measurements was applied to observe the impact of the infection on the spectral behaviour of PVY infected plants. An empirical-statistical approach was used for data analyses. Ten narrowband vegetation indices were used for monitoring the biophysical parameters and physiological state of plants. Each of them has a unique combination of wavebands in green, red and NIR spectral ranges that related to specific crop parameters. Eight VIs were found to be suitable for assessment the influence of PVY viral infection. MCARI, CARI and ChI green showed highest sensitivity to changes in the spectral behaviour of the infected plants. Only NDVI and PRI proved to be insensitive. The use of narrowband VIs affected by vegetation physiological processes (i.e. photosynthesis) allowed 
monitoring of the development of vegetation stress at the early state. The approach proposed in this study holds a strong potential for wide use in precision agriculture. It allows an estimation of changes in crop photosynthetic pigments without a priori knowledge of the canopy. Hyperspectral reflectance data can be used and exploited in order to find the specific wavebands that are most suitable for studying particular biophysical and biochemical properties.

\section{REFERENCES}

1. A. F. H. Goetz, B. C. Gao, C. Wessman, "Vegetation biochemistry: what can imaging spectrometry tell us about canopies?" in vol. 3 Proc. of the $6^{\text {th }}$ Australasian Remote Sensing Conference, Wellington, New Zealand, 1992, pp. 150-160.

2. L. Chaerle, D. van der Straeten, "Seeing is believing: Imaging techniques to monitor plant health," Biophys. Biochim. Acta - Gene Struct. Expr., vol. 1519, no. 3, pp. 153-166, Jun. 2001. DOI: 10.1016/So167-4781(01)00238-X

3. C. V. M. Barton, "Advances in remote sensing of plant stress," Plant Soil, vol. 354, no. 1-2. pp. $41-44$, May 2012.

DOI: 10.1007/s11104-011-1051-0

4. C. Panigada et al., "Chlorophyll concentration mapping with MIVIS data to assess crown discoloration in the Ticino Park oak forest," Int. J. Remote Sens., vol. 31, no. 12, pp. 3307-3332, Jul. 2010. DOI: $10.1080 / 01431160903193497$

5. F. Fava et al., "Identification of hyperspectral vegetation indices for Mediterranean pasture characterization," Int. J. Applied Earth Observ. and Geoinform., vol. 11, no. 4, pp. 233 - 243, Aug. 2009. DOI: $10.1016 /$ j.jag.2009.02.003

6. R. Colombo et al., "Estimation of leaf and canopy water content in poplar plantations by means of hyperspectral indices and inverse modelling," Remote Sens. Environ., vol. 112, no. 4, pp. 1820-1834, Apr. 2008. DOI: 10.1016/j.rse.2007.09.005

7. R. Colombo et al., "Retrieval of leaf area index in different vegetation types using high resolution satellite data”, Remote Sens. Environ., vol. 86, no. 1, pp. 120131, Jun. 2003. DOI: $10.1016 /$ Soo34-4257(03)0oo94-4

8. J. G. P. W. Clevers, L. Kooistra, "Using Hyperspectral Remote Sensing Data for Retrieving Canopy Chlorophyll and Nitrogen Content," IEEE Journal of Selected Topics in Applied Earth Observation and Remote Sensing, vol. 5, no. 2, pp. 574-583, Apr. 2012. DOI: 10.1109/JSTARS.2011.2176468

9. M. Meroni, R. Colombo and C. Panigada, "Inversion of a radiative transfer model with hyperspectral observations for LAI mapping in poplar plantations," Remote Sens. Environ., vol. 92, no. 2, pp. 195-206, Aug. 2004.

DOI: $10.1016 /$ j.rse.2004.06.005

10. F. C. Monteiro et al., "Assessing biophysical variable parameters of bean crop with hyperspectral measurements Priscylla," Sci. Agric., vol. 69, no. 2, pp. 87-94, Mar-Apr. 2012.

DOI: $10.1590 /$ So103-90162012000200001

11. P. J. Zarco-Tejada et al., "A PRI-based water stress index combining structural and chlorophyll effects: Assessment using diurnal narrow-band airborne imagery and the CWSI thermal index," Remote Sens. Environ., vol. 138, pp. 38-50, Nov. 2013. DOI: 10.1016/j.rse.2013.07.024

12. W. Verhoef, "Light scattering by leaf layers with application to canopy reflectance modeling: The SAIL model," Remote Sens. Environ., vol. 16, no. 2, pp. 125141, Oct. 1984.
DOI: 10.1016/0034-4257(84)90057-9

13. A. J. Berjón et al., "Retrieval of biophysical vegetation parameters using simultaneous inversion of high resolution remote sensing imagery constrained by a vegetation index," Precision Agric., vol. 14, no. 5, pp. 541-557, Oct. 2013.

DOI: $10.1007 / \mathrm{s} 11119-013-9315-8$

14. C.S.T. Daughtry et al., "Estimating corn leaf chlorophyll concentration from leaf and canopy reflectance," Remote Sens. Environ., vol. 74, no. 2, pp. 229-239, Nov. 2000.

DOI: 10.1016/Soo34-4257(00)00113-9

15. N. Petrov. V. Lyubenova, "Variability in P1 gene region of Potato virus $\mathrm{Y}$ isolates and its effect on potato crops," in Proc. Conf. The Man and the Universe, Smolyan, Bulgaria, 2011, pp. $671-677$.

Retrieved from:

https://www.researchgate.net/publication/260244852 variability in $\mathrm{p} 1$ gene region of potato virus $\mathrm{y} i$ solates and its effect on potato crops

Retrieved on: Jan. 20, 2017

16. D. Noordam, Identification of plant viruses: methods and experiments, 1st ed., Wageningen, The Netherlands: Centre for Agricultural Publishing and Documentation, 1973.

17. M. A. Aqeel Ashraf, M. J. Maach, I. Yusoff, "Introduction to Remote Sensing of Biomass," in Biomas and Remote Sensing of Biomass, I. Atazadeh, Ed., Rijeka, Croatia: InTech, 2011, ch. 8, sec. 1.5, p. 135. Retrieved from:

https://cdn.intechopen.com/pdfs-wm/19222.pdf Retrieved on: Jan. 20, 2017

18. G. R. Mahajan et al., "Using hyperspectral remote sensing techniques to monitor nitrogen, phosphorus, sulphur and potassium in wheat (Triticum aestivum L.)," Precision Agric., vol. 15, no. 5, pp. 499-522, Oct. 2014.

DOI: 10.1007/s11119-014-9348-7

19. D. Krezhova, A. Stoev and S. Maneva, "Detection of biotic stress caused by apple stem grooving virus in apple trees using hyperspectral reflectance analysis," Compt. rend. Acad. Bulg. Sci., vol. 68, no. 2, pp. 175182, Jun. 2015.

Retrieved from:

https://www.researchgate.net/publication/278406271 Detection of biotic stress caused by apple stem grooving virus in apple trees using hyperspectral reflectance analysis

Retrieved on: Jan. 20, 2017

20. D. A. Fuentes et al., "Mapping Canadian boreal forest vegetation using pigment and water absorption features derived from the AVIRIS sensor," J. Geophys. Res. vol. 106, no. D24, pp. 33565-33577, Dec. 2001. DOI: 10.1029/2001JD900110

21. D. Krezhova et al., "Detection of environmental changes using hyperspectral remote sensing," in Proc. of $9^{\text {th }}$ Int. Physics Conf. of the Balkan Physical Union (BPU9), Istanbul, Turkey, 2015. DOI: $10.1063 / 1.4944275$

22. USB200O Fiber Optic Spectrometer Installation and Operation Manual, Ocean Optics, Inc., Dunedin (FL), USA.

Retrieved from:

https://oceanoptics.com/wpcontent/uploads/USB2000-Operating-Instructions.pdf Retrieved on: Jan. 20, 2017

23. D. Krezhova et al., "Method for detecting stress induced changes in leaf spectral reflectance," Compt. Rend. Acad. Bulg. Sci., vol. 58, no. 5, pp. 517-522, 2005.

24. P. J. Zarco-Tejada et al., "Hyperspectral indices and model simulation for chlorophyll estimation in opencanopy tree crops," Remote Sens. Environ., vol. 90, no. 4, pp. 463-476, Apr. 2004. DOI: $10.1016 /$ j.rse.2004.01.017 
25. G. A. Carter, "Ratios of leaf reflectances in narrow wavebands as indicators of plant stress," Int. J. Remote Sens., vol. 15, no. 3, pp. 697-704, 1994. DOI: $10.1080 / 01431169408954109$

26. C. F. Jordan, "Derivation of leaf area index from quality of light on the forest floor," Ecology, vol. 50, no. 4, pp. 663-666, Jul. 1969. DOI: $10.2307 / 1936256$

27. D. R. Tilley, M. Ahmed, J. Son and H. Badrinarayanan, "Hyperspectral reflectance of emergent macrophytes as an indicator of water column ammonia in an oligohaline, subtropical marsh," Ecol. Eng., vol. 21, no. 2-3, pp. 153-163, Dec. 2003. DOI: $10.1016 / \mathrm{j}$.ecoleng.2003.10.004

28. C. J. Tucker, "Red and photographic infrared linear combinations for monitoring vegetation," Remote Sens. Environ., vol. 8, no. 2, pp. 127-150, May 1979. DOI: $10.1016 / 0034-4257(79) 90013-0$

29. J. W. Rouse et al., "Monitoring the vernal advancement of retrogradation of natural vegetation," NASA GSFC, Greenbelt (MD), USA, Rep. 1-371, 1974.

Retrieved from:

https://ntrs.nasa.gov/archive/nasa/casi.ntrs.nasa.gov/ 19740022555.pdf

Retrieved on: Jan. 21, 2017

30. A. D. Roberts, L. K. Roth and L. R. Perroy, "Hyperspectral Vegetation Indices," in Hyperspectral Remote Sensing of Vegetation, A. Thenkabail, P.S. Lyon, J. G. Huete Eds., Boca Raton (FL), USA: CRC Press, 2011, ch. 14, sec. 2, pp. 309-328. DOI: $10.1201 /$ b11222-20

31. C. Jurgens, "The modified normalized difference vegetation index (mNDVI) a new index to determine frost damages in agriculture based on Landsat TM data," Int. J. Remote Sens., vol. 18, no. 17, pp. 35833594, 1997. DOI: $10.1080 / 014311697216810$

32. M. N. Merzlyak et al., "Non-destructive optical detection of leaf senescence and fruit ripening," Physiol. Plant., vol. 106, no. 1, pp. 135-141, May 1999. DOI: $10.1034 /$ j.1399-3054.1999.106119.x

33. A. A. Gitelson, A. Viña, V. Ciganda, D. C. Rundquist, T. J. Arkebauer, "Remote estimation of canopy chlorophyll content in crops," Geophys. Res. Lett., vol. 32, no. 8, Apr. 2005

DOI: $10.1029 / 2005$ GLO22688

34. J. A. Gamon, J. Peñuelas, C. B. Field, "A narrowwaveband spectral index that tracks diurnal changes in photosynthetic efficiency," Remote Sens. Environ., vol. 41, no. 1, pp. 35-44, Jul. 1992.

DOI: $10.1016 / 0034-4257(92) 90059-S$

35. D. A. Sims, J. A. Gamon, "Relationships between leaf pigment content and spectral reflectance across a wide range of species, leaf structures and developmental stages," Remote Sens. Environ., vol. 81, no. 2-3, pp. 337-354, Aug. 2002.

DOI: $10.1016 /$ So034-4257(02)ooo10-X

36. D. Haboudane et al., "Integrated narrow-band vegetation indices for prediction of crop chlorophyll content for application to precision agriculture," Remote Sens. Environ., vol. 81, no. 2-3, pp. 416-426, Aug. 2002.

DOI: 10.1016/Soo34-4257(02)ooo18-4

37. M.S. Kim, C. S. T. Daughtry, E.W. Chappelle, J.E. McMurtrey, C. L. Walthall, "The use of high spectral resolution bands for estimating absorbed photosynthetically active radiation (Apar)," in Proc. of the $6^{\text {th }}$ Symposium on Physical Measurements and Signatures in Remote Sensing, Val D'Isere, 1994, pp. 299-306.

Retrieved from:

https://goobi.tib.eu/viewer/content/?action=pdf\&mets

file $=830289488 . x m l \&$ targetfilename $=$ the use of high spectral resolution bands for estimating absorbed photosynthetically active radiation apar moon $\mathrm{s}$

kim c s t daughtry e w chappelle je momurtrey and c l walthall.pdf

Retrieved on: Jan. 21, 2017

38. S. L. Ustin et al., "Remote sensing based assessment of biophysical indicators for land degradation and desertification," in Recent advances in remote sensing and geo-information processing for land degradation assessment, vol. 8, A. Röder, J. Hill, Eds., Boca Raton (FL), USA: CRC Press, 2009, ch. 2, pp. 15-44. Retrieved from:

https://books.google.ca/books?isbn=0203875443 Retrieved on: Jan. 21, 2017

39. D. Haboudane et al., "Hyperspectral vegetation indices and novel algorithms for predicting green LAI of crop canopies: Modeling and validation in the context of precision agriculture," Remote Sens. Environ., vol. 90, no. 3, pp. 337-352, Apr. 2004.

DOI: $10.1016 /$ j.rse.2003.12.013 